\title{
Congenital arteriovenous malformations: A follow-up of treatment
}

\author{
JH Phillips $M D^{1}$, CL Tang MD², D Armstrong MD,$T$ De Chalain $M D^{3}, \mathrm{R}$ Zuker $M D^{1}$
}

\author{
JH Phillips, CL Tang, D Armstrong, T De Chalain, R Zuker.
Congenital arteriovenous malformations: A follow-up of \\ JH Phillips, CL Tang, D Armstrong, T De Chalain, R Zuker.
Congenital arteriovenous malformations: A follow-up of \\ treatment. Can J Plast Surg 2005;13(1):23-26.
}

\begin{abstract}
Due to the rarity of arteriovenous malformations (AVMs), there is a paucity of information on the outcomes of various treatments. Presently, the mainstays of treatment of an AVM are embolization, surgical excision or a combination of both.

A retrospective study of 26 patients with AVMs treated at The Hospital for Sick Children, Toronto, Ontario between 1985 and 1995 was performed. The treatment strategies and patient outcomes were compared in terms of efficacy, complications and the response of patients and their families to their overall treatment.

The overall findings showed that embolization alone was effective in controlling symptoms, but may be associated with an increased AVM size. A partial excision of an AVM does not appear to exacerbate recurrence, as has been previously reported. In fact, even after what appears to be a complete excision of the AVM, recurrence may still occur. Complications from a surgical excision of the AVM are more frequent but less devastating than complications from embolization of the lesion. The overall patient or parent satisfaction with treatment was high with respect to improvement in outcome.

It is expected that with an increasing understanding of vascular malformations, and the evolution of interventional radiological techniques, complications will decrease and results as a whole will improve.
\end{abstract}

Key Words: Arteriovenous malformations; AVM; Embolization; Vascular malformations

\section{Malformations artérioveineuses congénitales : Suivi du traitement}

Compte tenu de leur rareté, on dispose de peu d'informations sur le résultat des divers traitements appliqués aux malformations artérioveineuses (MAV). À l'heure actuelle, le traitement d'une MAV repose sur l'embolisation, l'excision chirurgicale ou sur les deux approches combinées. Les auteurs ont procédé à une étude rétrospective de 26 cas de MAV traités au Hospital for Sick Children de Toronto, Ontario, entre 1985 et 1995. Les stratégies thérapeutiques et les résultats obtenus ont été comparés sur le plan de leur efficacité et de leurs complications, de même que sur le plan de la réponse des jeunes patients et de leurs parents au traitement dans son ensemble.

Les résultats globaux ont montré qu'utilisée seule, l'embolisation était efficace pour maîtriser les symptômes, quoique associée à une augmentation de la taille des malformations. L'excision partielle de ce type de malformation ne semble pas exacerber les récurrences, comme on l'avait d'abord cru. En fait, même après une excision soi-disant complète de la $\mathrm{MAV}$, la récurrence reste possible. Les complications de l'excision chirurgicale des MAV sont plus fréquentes mais moins dangereuses que les complications de leur embolisation. La satisfaction globale des jeunes patients ou de leurs parents à l'égard du traitement a été grande en ce qui a trait à l'amélioration du pronostic. On s'attend à ce qu'avec l'approfondissement des connaissances sur ces malformations vasculaires et l'évolution des techniques d'intervention radiologique, les complications diminuent et les résultats s'améliorent dans l'ensemble.

\footnotetext{
A rteriovenous malformations (AVMs) are rare vascular malformations. They are frequently mislabelled and, conversely, other vascular malformations are more often mislabelled AVMs. This occurs despite several good classification systems of vascular malformations (1-7). The diagnosis of AVMs can be made by history, angiography, computed tomography, magnetic resonance imaging (MRI) or pathology. In the present study, the clinical diagnosis was confirmed by angiography, MRI or biopsy, to ensure that we were treating true AVMs. The clinical definition of an AVM is a lesion that is usually present at birth and grows commensurately with the child. It may cause signs of pulsation and bruit. The angiographical criterion for diagnosis of AVM is a lesion with the appearance of both arterial and venous phases seen on the same angiogram image, indicating a high-flow lesion (1).
}

Pathology reveals an abnormal collection of arteries and veins with normal endothelium and a normal mast cell count.

The treatment of AVMs is controversial. Historical treatments have included compression garments (4) and ligation of the feeding vessels with (3) and without sclerotherapy (8). The current mainstays of treatment are embolization, surgery or preoperative embolization followed within $48 \mathrm{~h}$ by surgery.

Most clinicians think that embolization is performed only to decrease the size of the lesion in preparation for surgery, thus reducing intraoperative bleeding $(6,9-13)$. However, a second indication for embolization is a temporizing measure to reduce critical symptoms such as recurrent bleeding and congestive heart failure, or to avoid major deforming surgical treatment (14).

Over the past few years, there has been a significant improvement in embolization techniques with smaller

${ }^{1}$ The Hospital for Sick Children, University of Toronto, Toronto; ${ }^{2} 135$ Queen's Plate Drive, Suite 340, Etobicoke, Ontario;

${ }^{3}$ Regional Centre for Plastic and Reconstructive Surgery, Middlemore Hospital, Auckland, New Zealand

Correspondence: Dr John H Phillips, The Hospital for Sick Children, 555 University Ave, Room 5429, Toronto, Ontario M5G 1 X8.

Telephone 416-813-6197, fax 416-813-6637, e-mail jphillips002@sympatico.ca 
TABLE 1

\section{Patient demographics}

\begin{tabular}{lc}
\hline & $\mathbf{n}$ \\
\hline Total number of AVMs & 27 \\
Number of patients with treated & 26 \\
AVM and follow-up > one year & \\
Sex & \\
Male & 9 \\
Female & 17 \\
Presentation of AVM at birth & 11 of 27 \\
Age of presentation unknown & 3 of 27 \\
Average age of AVM presentation (if not at birth) & 2.5 years \\
Average age of first treatment of AVM & 8 years \\
Average time between presentation and first treatment & 5 years \\
Average length of follow-up & 7.5 years \\
Location of AVM & \\
\hline
\end{tabular}

\begin{tabular}{ll}
\hline Craniofacial AVMs $(\mathrm{n}=18)$ & 5 \\
Forehead & 1 \\
Scalp & 1 \\
Lip & 2 \\
Ear & 3 \\
Cheek & 1 \\
Tongue & 5 \\
Diffusely over face & \\
Extremity AVMs $(\mathrm{n}=9)$ & 1 \\
Hand & 3 \\
Foot & 1 \\
Ankle & 1 \\
Knee & 1 \\
Leg & 3 \\
\hline
\end{tabular}

AVM Arteriovenous malformations

catheters and a more selective embolization of vessels. There are several reports of previously small or not visualized collateral vessels opening up postembolization. Flow becomes redirected into these lower resistance channels, leading to recurrence which may be more severe than the original AVM $(6,15)$. The results presented here represent data from 1985 to 1995. It is appreciated that the results of embolization over the past 10 years have improved and complications decreased with newer embolization techniques.

There is a paucity of information about the treatment outcome of AVMs. Although other investigators (1-6) have reported on the management of a series of AVMs, the present study is, to our knowledge, one of the largest series of treated AVMs. There are several difficulties in studying these problems, because the rarity of AVMs limits clinical experience with management. Also, treatment effect is difficult to isolate from confounding factors, such as trauma, hormonal changes or previous treatments and sporadic follow-ups.

\section{METHODS}

Patients with AVMs treated at The Hospital for Sick Children, Toronto, Ontario were identified through medical records. Intracerebral and visceral AVMs were excluded. A minimum of five years was chosen as adequate follow-up.

A chart review using a standardized form was performed to obtain patient data concerning the location of the AVM, method of diagnosis, symptoms, functional effects, treatment and outcome.
Symptoms included discolouration, bleeding, pain, pulsation, ulceration and bruits. Functional effects were problems with auditory, respiratory or visual obstruction, jaw or limb growth, feeding, speech, dental problems, limitation of activity, congestive heart failure or other functions. These data constituted the basis for the vascular malformation clinical database. As expected, not all data were available in every chart reviewed.

After basic demographic and clinical data collection, attention was turned to data pertaining to special investigations. If performed, the angiograms of the patients were reviewed by an angiographer and the investigator to ensure that the lesion was indeed an AVM. The arterial and venous phase had to be seen on the same angiogram image for the lesion to be called an AVM (1). MRIs of the AVM were also reviewed, if available.

A telephone interview was then performed by the junior author using a standardized questionnaire. The questions asked included: How did the treatment affect the size of the AVM (gone, better, same or worse)? What symptoms did the patient have and how were they affected by treatment (gone, better, same or worse)? Were there any functional effects caused by the AVM and how were they affected by the treatment (gone, better, same or worse)? Prompts were given when asking about symptoms and functional effects. Was there discolouration, bleeding, pain, pulsation, ulceration, bruit or other symptoms? Did the patient have problems with auditory, respiratory or visual obstruction, jaw or limb growth, feeding, speech, dental problems, limitation of activity, congestive heart failure or other effects? How long-lasting was the effect of the treatment?

Questions were developed by consulting several staff plastic surgeons. For each treatment performed, these questions were asked, so that if the patient had two treatments, then the same questions were asked twice. Patients were questioned if they were older than 13 years of age at the time of their treatment, and if they were available, otherwise the parents were questioned. Effect of treatment was rated at two years regardless of the effectiveness in the interim. For example, if there was improvement in the pulsation for two months, but then it recurred to the same level as pretreatment, the effect of the treatment was rated as 'same'. Data from the chart were used to supplement the results of the telephone survey. Finally, patients were asked about overall satisfaction (unsatisfied, slightly satisfied, satisfied or very satisfied) with the outcome of treatment at the hospital.

\section{RESULTS}

Twenty-nine patients were treated for their AVM between 1985 and 1995. The treatment was administered by eight different physicians from plastic surgery, radiology, otolaryngology, orthopedics or neurosurgery. Three patients had follow-ups of less than one year and were eliminated from part of the study. Of the remaining 26 patients, 17 were female and nine were male. One patient had two distinct AVMs and these were considered as separate lesions. Demographic data are shown in Table 1. Of the 27 AVMs, 18 were craniofacial and nine were on the extremities. Table 2 lists the symptoms and functional effects caused by the AVM. Telephone follow-ups were obtained in $100 \%$ of the 29 patients. Information was taken from eight patients and 21 parents.

Of the 27 AVMs, diagnosis was confirmed by angiogram in 22 cases, and by biopsy in two cases. In three of the 27 AVMs, diagnosis was made MRI and biopsy. Twelve of 27 AVMs were treated only once, while 15 had multiple treatments. An embolization treatment may have consisted of multiple 
embolization procedures, but if these were performed within one year of each other, they were grouped as a single embolization treatment.

Data were analyzed by viewing each treatment of an AVM as a separate event and responses to treatment were compared in terms of AVM size, symptoms and functional effects. Note that for purposes of the present analysis, treatments before the study period were ignored.

The first treatment considered was embolization. Nineteen patients were embolized a total of 27 times. Each embolization treatment was considered as a separate event. In some patients, an embolization treatment was performed more than once or they may have also been treated with another modality at some other time. As stated previously, an embolization treatment may have involved several embolization procedures, each performed consecutively within a year of each other. This group excluded patients treated by preoperative embolization. Embolization effectiveness was assessed by post-treatment imaging using angiograms or MRI. Embolization obliterated the lesion in two of 27 (7\%) treatments. In one-third of the cases, embolization reduced but did not obliterate the AVM. In over one-half of all embolizations, the size of the AVM was unchanged. In two of 27 patients, the AVM increased in size postembolization. Symptoms caused by the AVM (Table 2) were eliminated in $17 \%$ and improved in $55 \%$ of patients after embolization. Functional effects (auditory, respiratory or visual obstruction, jaw or limb growth, feeding, speech, dental problems, limitation of activity, congestive heart failure) were eliminated or improved in 33\% of patients.

The second AVM treatment considered was surgery. In all 14 treatments, surgery either decreased the size (43\%) or obliterated $(57 \%)$ the AVM, as demonstrated by postsurgical angiograms or MRI. Additionally, surgery improved (14\%) or eliminated $(64 \%)$ sympotoms in most treatments, with two (14\%) treatments showing no change in symptoms, as well as one treatment followed by a worsening of symptoms. The results of preoperative embolization and surgery are similar to that of surgery alone. Other treatments included laser therapy, steroid injection, cautery of the lesion and external carotid artery ligation. Generally, these procedures did not affect the AVM.

\section{DISCUSSION}

We recognize that because of patient recall bias and the retrospective nature of the present study, there are several flaws. Furthermore, the fact that patients were preselected into dissimilar treatment groups made direct comparisons difficult. Nevertheless, it is unlikely that a prospective, randomly assigned study of AVM treatment outcome will be performed. Although AVMs are supposed to grow proportionately with the child, they can be affected by hormonal changes, trauma and by the treatment itself. If an AVM is treated and it increases in size, it is difficult to know if the treatment has worsened the AVM by the development of collateral circulation, or the treatment actually helped by slowing down the natural growth of the AVM. In the present study, we assumed that the treatment resulted in a change in the AVM.

The concept that embolization can be used as a temporizing measure to reduce the critical symptoms of recurrent bleeding, or delay or prevent deforming surgical ablation, is supported by our study (14). Over the last few years, there has been a significant improvement in embolization techniques with smaller

\section{TABLE 2}

Symptoms and functional effects

\begin{tabular}{lc}
\hline Symptoms, $\mathrm{n}(\%)$ & 11 of $27(41)$ \\
Pulsation & 10 of $27(37)$ \\
Pain & 8 of $27(30)$ \\
Discolouration & 8 of $27(30)$ \\
Bleeding & 5 of $27(19)$ \\
Bruit & 3 of $27(11)$ \\
Ulceration & 1 of $27(4)$ \\
Warmth & \\
Functional effects, $\mathrm{n}(\%)$ & 3 of $27(11)$ \\
Hearing problems & 2 of $27(7)$ \\
Respiratory problems & 2 of $27(7)$ \\
Feeding problems & 1 of $27(4)$ \\
Speech problems & 1 of $27(4)$ \\
Eye problems & 2 of $27(7)$ \\
Congestive heart failure & 1 of $27(4)$ \\
Orthognathic growth & 3 of $27(11)$ \\
Limited function or activity & 1 of $27(4)$ \\
Leg length discrepancy & \\
\hline
\end{tabular}

catheters and the more selective embolization of vessels, such that further improvements in embolization treatment alone may be expected.

The reports of recurrence following embolization alone were also found in the present study in two of the 27 embolizations performed. One patient had an ear AVM embolized, initially decreasing the AVM size, however, after one month, the AVM enlarged to a size greater than pretreatment. There was no effect of embolization on the symptoms, or any subsequent hearing problems thereafter. The patient, who is otherwise well, has not undergone any further treatments. The second patient was treated with embolization for a cheek AVM. Following the treatment, the AVM enlarged but the associated bleeding stopped. The patient was treated with preoperative embolization and surgery six years later. This eliminated both the lesion and the symptoms.

At the Hospital for Sick Children, Toronto, Ontario, surgery was recommended if the AVM could be completely removed with a reasonable cosmetic defect. Occasionally, amputations have been reported if symptoms are so severe that they outweigh the deformity created by surgery $(4,6,8,12)$. There are reports that the partial excision of an AVM can cause proximal extension and worsening of the AVM $(6,16,17)$. Nine partial excisions, with or without preoperative embolization, were performed on six AVMs, with an average follow-up of five years. Partial excision did not appear to cause growth of the AVM or to worsen the symptoms. Size and symptoms of the AVM were improved by partial excision in eight of the nine cases.

Complete excision of the AVM was performed on nine lesions with an average follow-up of five years. Recurrence was noted in two AVMs. One patient had a below-the-knee amputation and had recurrence at the end of the stump after three years. Another patient had an approximately $24 \mathrm{~mm}$ AVM on her forehead without bone involvement. Six years later, she had a recurrence at the edge of the old lesion. Gelberman and Goldner (17) found that the most accurate predictor of the 
TABLE 3

\section{Complications of treatment}

\begin{tabular}{l} 
Surgery ( $n=14$ ) \\
Superior oblique muscle paralysis \\
Numbness \\
Postoperative infection \\
Bleeding requiring blood transfusion \\
Hepatitis B from blood transfusion \\
Wound dehiscence in two patients \\
Failure to take skin graft \\
Neuroma \\
Hypertrophic scar \\
Embolization ( $n=27$ ) \\
Lower facial palsy \\
Blindness (monocular visual loss) \\
Cerebral infarct causing hemiparesis \\
Preoperative embolization and surgery ( $n=6)$ \\
Numbness and palsy of frontalis muscle \\
Scalp flap infection and necrosis \\
\hline
\end{tabular}

results of surgery was the diffuseness of the AVM. Discrete soft tissue lesions respond well to excision, and AVMs with bone involvement appear to recur after excision or amputation. In general, even partial excision surgery improved the size and symptoms of the AVM. In only one patient, who had a small lip AVM completely excised, did symptoms worsen; this included a scar which resulted in pain when bitten.

The third treatment option was preoperative embolization, followed by either partial or complete excision of the AVM within $24 \mathrm{~h}$. This was performed six times in five patients and improvement in the AVM size was similar to the results of

\section{REFERENCES}

1. Jackson IT, Carreno R, Potparic Z, Hussain K. Hemangiomas, vascular malformations and lymphovenous malformations: Classification and methods of treatment. Plast Reconstr Surg 1993;91:1216-30.

2. Gomes AS. Embolization therapy of congenital arteriovenous malformations: Use of alternate approaches. Radiology 1994;190:191-8.

3. Chen MT, Horng SY, Yeong EK, Pan QD. Treatment of high-flow vascular malformations in the head and neck with arterial ligation followed by sclerotherapy. Ann Plast Surg 1996;36:147-53.

4. Carr MM, Mahoney JL, Bowen CV. Extremity arteriovenous malformations : Review of a series. Can J Surg 1994;37:293-9.

5. Widlus DM, Murray RR, White RI II, et al. Congenital arteriovenous malformations: Tailored embolotherapy. Radiology 1988;169:511-6.

6. Flye MW, Jordan BP, Schwartz MZ. Management of congenital arteriovenous malformations. Surgery 1983;94:740-7.

7. Mulliken JB, Glowacki J. Hemangiomas and vascular malformations in infants and children: A classification based on endothelial characteristics. Plast Reconstr Surg 1982;69:412-22.

8. Halliday AW, Mansfield AO. Congenital arteriovenous malformations. Br J Surg 1993;80: 2-3.

9. Vaughan M, Hennessy O, Jamieson C, Hemmingway AP, Allison DJ. The pre-operative embolisation of vascular malformations. $\mathrm{Br} \mathrm{J}$ Radiol 1985;58:717-20.
TABLE 4

Overall patient/parent satisfaction with treatment

\begin{tabular}{lc}
\hline Not satisfied, $\mathrm{n}(\%)$ & 4 of $26(15)$ \\
Slightly unsatisfied, $\mathrm{n}(\%)$ & 0 of $26(0)$ \\
Satisfied, $\mathrm{n}(\%)$ & 10 of $26(38)$ \\
Very satisfied, $\mathrm{n}(\%)$ & 12 of $26(46)$ \\
\hline
\end{tabular}

surgery alone, proving effective at controlling symptoms. In one patient, an eliminated AVM reappeared after five years and was successfully treated with repeated embolization.

Table 3 lists the complications of all procedures. It is obvious that neither embolization nor surgery is a completely benign treatment. Although we tend to think of embolization as less invasive, a complication can be devastating.

In our survey of the overall patient satisfaction (Table 4), it was found that most patients were either satisfied (10 of 26) or very satisfied (12 of 26). Surprisingly, patients with the more severe AVMs were most satisfied with the overall treatment. The reasons listed for dissatisfaction with treatment included feelings of loss of control while the patient was in hospital, poor communication about the treatment or post-treatment care, and how emergencies, like bleeding, were handled.

\section{CONCLUSIONS}

The outcome of treatment of AVMs is a difficult problem to study. From the present retrospective study, we found that embolization can cause an apparent increase in AVM size, however, in most cases, embolization alone is effective at controlling symptoms. Partial excision did not appear to worsen the size or symptoms of the AVM, and even after what appears to be a complete excision of the AVM, recurrences can occur. The overall patient or parent satisfaction with treatment was high with respect to improvement in outcome.

10. Bryant RS, Russell EJ, Curtin JW. Combined treatment of arteriovenous malformations by transarterial microembolization and surgery. Am Surg 1988;54:637-42.

11. Persky MS, Berenstein A, Cohen NL. Combined treatment of head and neck vascular masses with preoperative embolization. Laryngoscope 1984;94:20-7.

12. Schwartz GB, Nunley JA. Congenital arteriovenous malformation of the hand. Orthop Rev 1987;16:101-5.

13. Kane WJ, Morris S, Jackson IT, Woods JE. Significant hemangiomas and vascular malformations of the head and neck: Clinical management and treatment outcomes. Ann Plast Surg 1995; 35:133-43.

14. Burrows PE, Lasjaunias PL, Ter Brugge KG, Flodmark O. Urgent and emergent embolization of lesions of the head and neck in children: Indications and results. Pediatrics 1987;80:386-94.

15. Perrott DH, Schmidt B, Dowd CF, Kaban LB. Treatment of a highflow arteriovenous malformation by direct puncture and coil embolization. J Oral Maxillofac Surg 1994;52:1083-6.

16. Upton J, Mulliken JB, Murray JE. Classification and rationale for management of vascular anomalies in the upper extremity. J Hand Surg 1985;10A:970-5.

17. Gelberman RH, Goldner JL. Congenital arteriovenous fistulas of the hand. J Hand Surg 1978;3:451-4. 